\title{
Enantioselective Functionalization of Internal Alkenes
}

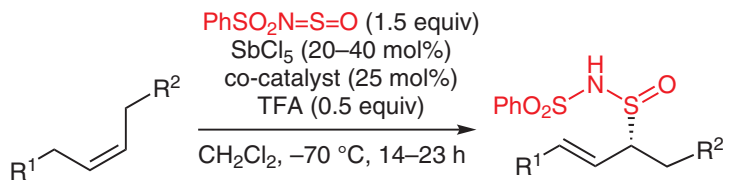

Selected examples:

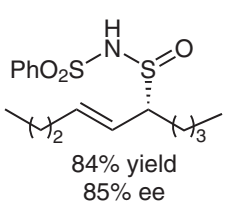<smiles>O=C(OCC(C=CCOS(=O)(=O)O)S(=O)NS(=O)(=O)OC(=O)C(F)(F)F)C(F)(F)F</smiles><smiles>C/C=C\[GaH][Po]</smiles><smiles>CI</smiles><smiles>CC(/C=C/C(=O)OCc1ccccc1)S(=O)NS(=O)(=O)c1ccccc1</smiles>

$54 \%$ yield

$$
\text { rr }>20: 1
$$

BINOL was used instead of co-catalyst

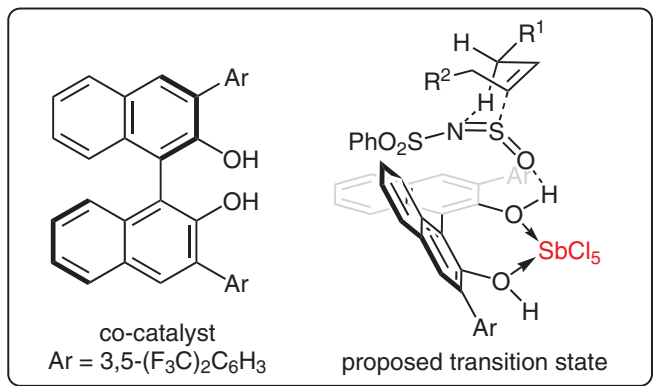<smiles>CC(C)/C=C\Cc1ccccc1</smiles>

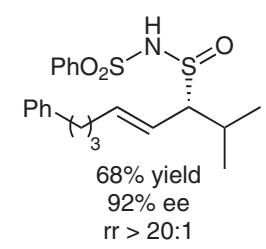<smiles>CP/C=C\CCCl</smiles><smiles>CC/C=C/[C@H](CCCl)S(=O)NS(=O)(=O)c1ccccc1</smiles>

$59 \%$ yield $86 \%$ ee rr $>20: 1$

Transformation of product:

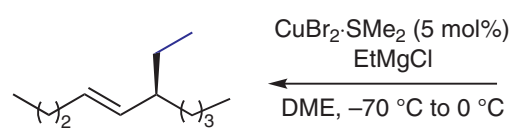

$73 \%$ yield $100 \%$ enantiospecificity $r r=3: 1(\alpha / \gamma)$

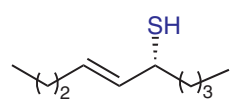

$72 \%$ yield $100 \%$ enantiospecificity

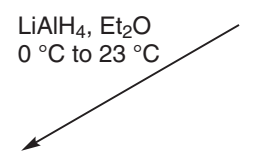

$\mathrm{LiAlH}_{4}, \mathrm{Et}_{2} \mathrm{O}$
$0{ }^{\circ} \mathrm{C}$ to $23^{\circ} \mathrm{C}$

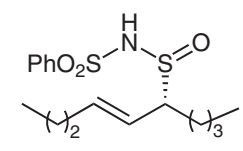

$84 \%$ yield
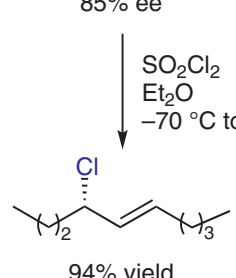

$94 \%$ yield

$95 \%$ enantiospecificity

$r r=3: 1(\gamma / \alpha)$

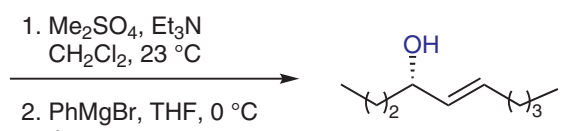

then

$\mathrm{P}(\mathrm{OMe})_{3}, \mathrm{MeOH}, 23^{\circ} \mathrm{C}$
Category

Metal-Catalyzed

Asymmetric

Synthesis and

Stereoselective

Reactions

\section{Key words}

antimony catalysis

allylic oxidation

hetero-ene reaction

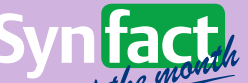
the war

Significance: The authors developed an enantioselective introduction of electrophilic oxidants into internal alkenes by using a hetero-ene reaction. A Lewis-acid-assisted Brønsted-acid system enables this transformation with high selectivity.

sYNFACTS Contributors: Hisashi Yamamoto, Yasushi Shimoda Synfacts 2017, 13(10), 1039 Published online: 18.09.2017 Dol: 10.1055/s-0036-1591304; Reg-No.: H11517SF
Comment: The utility of this transformation was demonstrated by the derivatization of the products to give various valuable chiral compounds. A reaction mechanism is proposed on the basis of mechanistic experiments. 